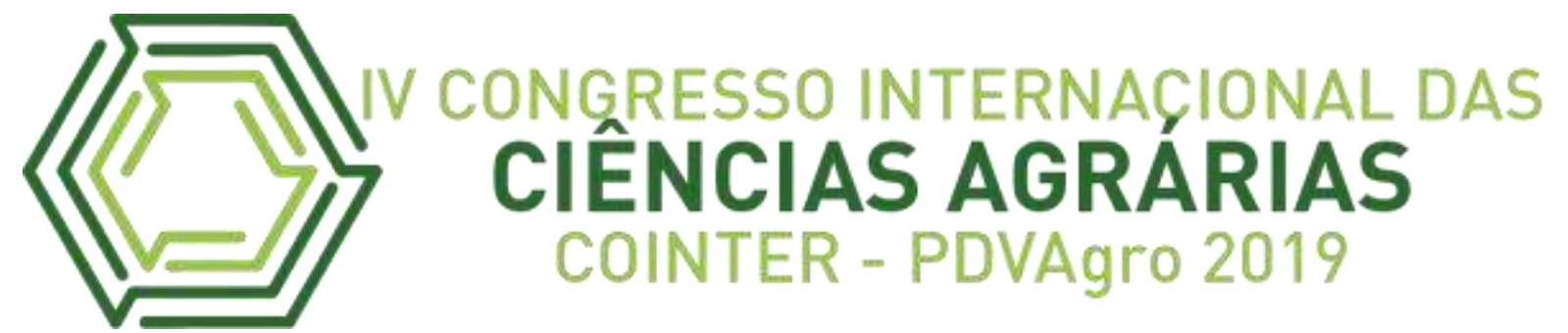

\title{
DESEMPENHO DAS EXPORTAÇÕES DE MADEIRA NO ESTADO DO PARÁ, NO PERÍODO DE 2000 A 2015.
}

\author{
RENDIMIENTO DE LAS EXPORTACIONES DE MADERA EN EL ESTADO DE \\ PARÁ, DE 2000 A 2015.
}

\section{PERFORMANCE OF WOOD EXPORTS IN THE STATE OF PARÁ, FROM 2000 TO 2015.}

\author{
Apresentação: Comunicação Oral
}

Roberta Marselle Santos Rodrigues ${ }^{1}$; João Guilherme da Silva Filho ${ }^{2}$; Lucas Belém Tavares ${ }^{3}$ Caroline Barbosa Nobre ${ }^{4}$; Jaime Borge da Cunha Junior ${ }^{5}$

DOI https://doi.org/10.31692/2526-7701.IVCOINTERPDVAgro.2019.0182

\begin{abstract}
Resumo
O Estado do Pará apresenta em seu território diversas áreas de exploração de madeira, apresentando no decorrer dos anos um aumento no desmatamento. Com a implantação da Lei $\mathrm{n}^{\circ}$ 11284/06 houve a diminuição da exploração ilegal de madeira, intensificando-se com a Operação Arco de Fogo, demonstrado assim a importância de órgãos fiscalizadores, como o IBAMA E SEMAS-PA. Neste sentido, o presente trabalho objetivou estudar as variáveis de exportação de madeira no Estado do Pará, no período de 2000 a 2015. Os dados foram coletados na plataforma on-line do Ministério da Indústria, Comércio Exterior e Serviços (MDIC), disponibilizados no Sistema do MDIC de Estatística do Comercio Exterior (Comex Stat), que são extraídas do SISCOMEX e baseados na declaração de exportadores e importadores. Foram classificados em quatro categorias sendo: madeira compensada, madeira serrada, madeira bruta (Coníferas) e movelaria. Os resultados para madeira bruta (conífera) a média de peso exportada obtida foi de 742 Toneladas $( \pm 27,24)$, com máxima de 3045 Toneladas no ano de 2002 e mínima de 9,8 Toneladas em 2013. O setor de exportação no Estado apresentou muita variação, onde o percentual de madeira na balança comercial de exportação variou entre $8,8 \%$ a $0,6 \%$ neste intervalo de anos. Tal variação se deu por conta de diversos fatores, dentre eles ao aumento de operações fiscalizadoras, para o combate ao desmatamento na Amazônia. Os dados expostos no trabalho evidenciam que no mercado há uma grande influência do valor associado aos produtos de madeira, e com a sua legalização, sua grandeza agrega mais valor à produção.
\end{abstract}

\footnotetext{
${ }^{1}$ Graduanda em Engenharia Agronômica, UFRA, roberta.ms.rodrigues0@gmail.com

${ }^{2}$ Graduando em Engenharia Agronômica, UFRA, joaoguilherfilhoo@gmail.com

${ }^{3}$ Graduando em Engenharia Florestal, UFRA, lucasbelemtavares@gmail.com

${ }^{4}$ Graduanda em Engenharia Florestal, UFRA, Caroline_nobre00@hotmail.com

${ }^{5}$ Graduando em Engenharia Florestal, UFRA, jaimebcjr@gmail.com
} 
Palavras-Chave: Mercado, Balança Comercial, Cadeia Produtiva.

\begin{abstract}
Resumen
El Estado de Pará tiene en su territorio varias áreas de tala, lo que muestra a lo largo de los años un aumento de la deforestación. Con la implementación de la Ley $\mathrm{N}^{\circ}$ 11284/06 hubo una disminución en la tala ilegal, intensificándose con la Operación Arco de Fuego, lo que demuestra la importancia de las agencias de aplicación, como IBAMA y SEMAS-PA. En este sentido, el presente trabajo tuvo como objetivo estudiar las variables de exportación de madera en el Estado de Pará, de 2000 a 2015. Los datos se recopilaron en la plataforma en línea del Ministerio de Industria, Comercio Exterior y Servicios (MDIC), disponible en el Sistema de Estadísticas de Comercio Exterior de MDIC ( Comex Stat ), que se extraen de SISCOMEX y se basan en la declaración de exportadores e importadores. Se clasificaron en cuatro categorías: madera contrachapada, madera, madera en bruto (coníferas) y muebles . Los resultados para la madera cruda (coníferas) el peso promedio de exportación obtenido fue de 742 toneladas ( \pm 27.24 ), con un máximo de 3045 toneladas en el año 2002 y un mínimo de 9.8 toneladas en 2013. El sector exportador en E Hubo mucha variación, donde el porcentaje de madera en la balanza comercial de exportación varió de $8.8 \%$ a $0.6 \%$ durante este período de años. Esta.
\end{abstract}

Palabras clave: Mercado, Balanza Comercial, Cadena Productiva.

\begin{abstract}
Summary
The State of Pará has in its territory several areas of logging, showing over the years an increase in deforestation. With the implementation of Law No. 11284/06 there was a decrease in illegal logging, intensifying with Operation Arc of Fire, thus demonstrating the importance of enforcement agencies such as IBAMA and SEMAS-PA. In this sense, the present work aimed to study the wood export variables in the State of Pará, from 2000 to 2015. Data were collected on the online platform of the Ministry of Industry, Foreign Trade and Services (MDIC), available at MDIC System of Foreign Trade Statistics (Comex Stat), which are extracted from SISCOMEX and based on the declaration of exporters and importers. They were classified into four categories: plywood, lumber, raw wood (Conifers) and furniture. The results for crude (coniferous) wood the average export weight obtained was 742 Tons ( \pm 27.24), with a maximum of 3045 Tons in the year 2002 and a minimum of 9.8 Tons in 2013. The export sector in the State showed a great variation, where the percentage of wood in the export trade balance ranged from $8.8 \%$ to $0.6 \%$ in this period of years. This variation was due to several factors, including the increase in enforcement operations to combat deforestation in the Amazon. The data exposed in the work show that in the market there is a great influence of the value associated with wood products, and with its legalization, its greatness adds more value to production.
\end{abstract}

Keywords: Market, Trade Balance, Productive Chain.

\title{
Introdução
}


A exploração da madeira no século XVII e XVIII ocorreu em alta, devido a descoberta de espécies e havendo um grande interesse econômico para coroa Portuguesa, e assim, desempenhando um papel muito importante para o crescimento do mercado interno e externo na Amazônia (HOMMA, 2014). Essa atividade, acarretou na implantação de diversas áreas, tais como, práticas de colheitas agrícolas.

Por este motivo, o uso das tecnologias aumentou nos últimos anos, em que se obteve um alto grau de recursos no setor florestal, como exemplo as máquinas que vieram substituir o papel do homem no seu trabalho. E devido a isso, o setor madeireiro veio crescendo e ganhando um potencial produtivo. Encontram-se várias pesquisas e estudos no desenvolvimento da exploração da madeira, fazendo assim, parte de um processo histórico, social e até mesmo de benefícios econômicos (MAZZOCHIN, 2013).

Dessa maneira, o Pará é destaque em grande fornecimento de madeira tropical, se comparado com o restante do Brasil. Porém, a parti de 2008, ocorreu o aumento das fiscalizações com maior vitalidade e havendo também a outorga do plano de manejo (PMFS) (OLIVEIRA \& ANDRADE, 2015).

Sabe-se que esta aprovação, tem parceria com o SISFLORA-PA (Sistema de Comercialização e Transporte de Produtos Florestais), o CEPROF (Sistema de Cadastro de Consumidores de Produtos Florestais) e com a Secretaria Estadual de Meio Ambiente (SEMA-PA), que tem como objetivo orientar e fiscalizar os setores madeireiros e a forma com que o transporte é comercializado, e que neste foi estabelecido através do Decreto Estadual n² 2.592 em 27 de novembro de 2006 (OLIVEIRA \& ANDRADE, 2015).

Observa-se também, que a exploração da madeira é importante, trazendo consigo pontos positivos, por exemplo na ampliação do Produto Interno Bruto (PIB), se conduzida através de práticas e manejo sustentável (SIMÕES et al, 2015).

Porém, com as altas taxas de desmatamentos, realizou-se em março de 2008 a Operação Arco de Fogo, com o intuito de diminuir a extração e o desmatamento ilegal da madeira (IBAMA, 2008), essa ação esteve em conjunto com o IBAMA, a Polícia Federal e a Força Nacional de Segurança e Governo do Estado do Pará. Essa atividade objetivou em um reflexo drástico no declínio da exploração de madeira no estado do Pará, causando um aumento maior nas fiscalizações pelo IBAMA E SEMAS-PA (ARAÚJO, 2015).

Neste sentido, o objetivo desse trabalho é analisar a cadeia produtiva e verificar o desempenho do mercado de exportação de madeira no Estado do Pará, no período de 2000 a 
2015.

\section{Fundamentação Teórica (Cadeia Produtiva da Madeira no Pará).}

O conjunto de atividades econômicas que circundam em torno da gestão, da extração, da exploração da floresta, da comercialização e da transformação da madeira é chamado de cadeia produtiva da madeira, sendo um setor de atividades imenso, que vai desde a colheita da semente para se produzir mudas, em viveiro, até a impressão de jornais e revistas com papel à base de madeira, ou fabricação de diversos tipos de móveis e utensílios.

Segundo Buainain e Batalha (2007) no mundo inteiro o setor florestal tem importância como fornecedor de energia ou matéria-prima para a indústria da construção civil e de transformação, no Brasil apresenta ainda características mais singulares em razão do fato de o País estar entre os principais detentores de recursos florestais abundantes, sendo o único que possui extensa área de florestas tropicais. Desse modo ampliando sua participação na produção e no comércio, essa tendência, contudo, é progressivamente colocada em aberto pelas crescentes dificuldades que as empresas enfrentam de ampliar seus negócios, especialmente na região amazônica.

Nesse contexto, a partir da extração da matéria-prima florestal tem início a cadeia produtiva florestal por meio do processamento primário, seguindo da geração de produtos florestais. Estes podem ser madeireiros, notadamente na forma de madeira em tora e de principal interesse para a indústria baseada nas florestas comerciais (plantas ou nativas), ou não madeireiras.

Nas florestas de terra firme, o sistema de exploração é geralmente mecanizado, sendo caracterizado pelo corte das árvores através de motosserras e o arraste de toras feito por tratores. Há uma diversidade de tipos de tratores, sendo que o uso de tratores de esteira ainda é a forma mais comum (49\% do volume de madeira extraído é arrastado por este tipo de máquina), seguido por tratores de pneus tipo skidder (27\%) e tratores agrícolas (6\%). Além disso, cerca de $11 \%$ da madeira extraída foi arrastada através do sistema "catraca", no qual as toras são embarcadas em caminhões com auxílio de cabos de aço. O sistema manual, caracterizado pelo uso do machado no corte e arraste feito com as mãos (em geral, grupos de dez a quinze pessoas fazem essa operação) estava restrito ao estuário e representou somente 7\% do volume extraído no Estado. (IMAZON, 2015)

A Amazônia Legal é a região que abriga o maior número de indústrias da cadeia produtiva do manejo sustentável de florestas naturais, com 71 polos de produção, que 
englobam 2,2 mil indústrias. Os estados com maior número de indústrias são o Pará (48\%), Mato Grosso (27\%) e Rondônia (16\%). De junho de 2016 a maio de 2017, a indústria madeireira da Amazônia Legal gerou aproximadamente 42 mil empregos diretos, os quais ocorrem na fase de exploração florestal e processamento da madeira, e 70 mil foram empregos indiretos (SFB, 2015).

Segundo Santana et al. (2012), o dimensionamento do valor econômico da floresta manejada e sua comparação com as principais alternativas de uso da terra na Amazônia (pecuária extensiva e agricultura de grãos) revelam resultados que confirmam a hipótese de que a exploração sustentável da floresta é mais rentável do que as atividades agropecuárias que, para serem implantadas, exigem a retirada da floresta.

Figura 1. Possibilidades de inter-relação da cadeia produtiva no setor florestal.

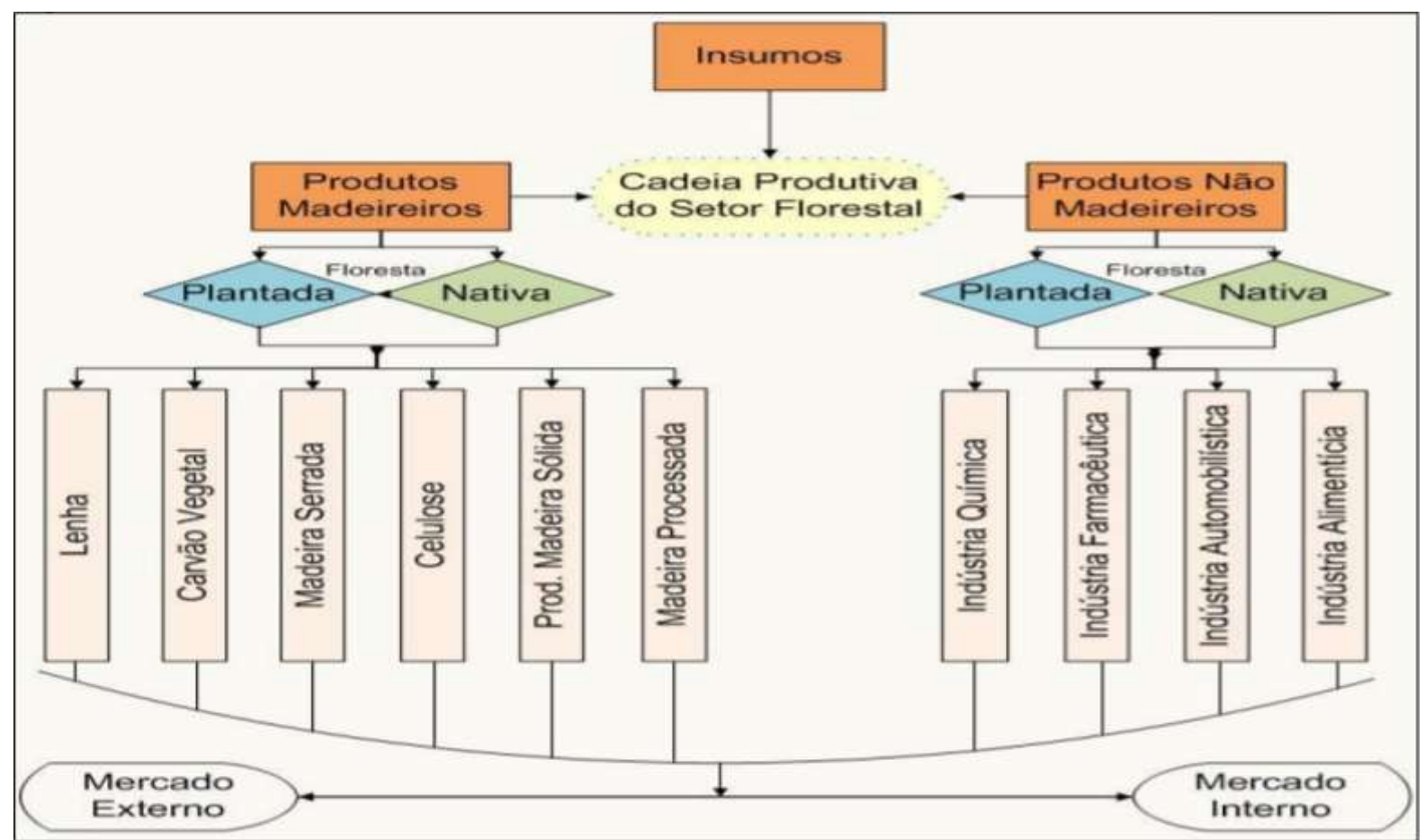

Fonte: Sistema Nacional de Informações Florestais (SFB, 2019).

O processamento da madeira dentro da indústria se divide em primário, secundário e terciário, cada um seguindo um fluxo próprio de acordo com o seu respetivo segmento. $\mathrm{O}$ processo primário se refere ao desdobro da tora, dando origem aos seguintes produtos: cavaco, madeira serrada, madeira laminada, madeira imunizada e carvão vegetal, além de energia. Estes darão origem a outros produtos diferenciados de acordo com o segmento industrial específico. A fase subsequente é o processamento secundário, que consiste no beneficiamento 
dos produtos oriundos da primeira transformação em produtos finais, ou intermediários a outros processamentos. Os primeiros produtos a partir da madeira serrada, que pode ser destinada diretamente ao consumidor final, são as vigas, caibros, ripas, madeira tratada e também caixotaria. Outro produto da transformação secundária da lâmina de madeira, seja ela torneada ou faqueada, é o compensado decorativo ou estrutural. Também poderá seguir no fluxo, transformando-se em partes para pisos laminados. O cavaco é a matéria prima para as indústrias de painéis reconstituídos, seja o MDF, o MDP ou o OSB. O cavaco e a casca das árvores têm ampla utilização na queima direta para atender diferentes processos de geração de energia. O processamento terciário é a fase que agrega maior valor econômico ao produto madeireiro, e também o mais próximo das necessidades específicas do consumidor final. Os produtos derivados da celulose (processamento secundário) possuem alto grau de agregação de valor, como os diversos tipos de papel para impressão, papéis cartão, os papelões ondulados para embalagens, dentre outros. Atualmente pode-se encontrar no mercado os tecidos feitos de celulose, resultado de altas tecnologias e pesquisas aplicadas ao setor.

A cadeia produtiva pode-se subdividir dependendo da sua atividade a qual se destina como: a subcadeia da madeira para energia, a subcadeia da madeira para processamento mecânico, e a subcadeia da madeira de aplicação industrial. Pois existem vários fins para essa utilização como lenha, carvão vegetal, papel e celulose, fabricação de móveis, construção civil entre outros. Sendo a cadeia produtiva de celulose e papel de grande importância na economia brasileira, devido ao impacto significativo que a mesma exerce sobre inúmeras outras cadeias produtivas.

A grande maioria (89\%) das 676 madeireiras era formada por serrarias equipadas com serras-de-fita, enquanto as laminadoras somavam $6 \%$ e as fábricas de compensados, $5 \%$. A madeira serrada representou 3,26 milhões de metros cúbicos $(77 \%)$ da produção madeireira do Estado. Por sua vez, os laminados totalizaram 408 mil metros cúbicos (10\%), os compensados somaram 329 mil metros cúbicos (7\%) e a madeira beneficiada, 253 mil metros cúbicos $(6 \%)$.

O Pará abriga também 534 serrarias circulares (em geral, microempresas informais) localizadas majoritariamente na região do estuário paraense e baixo Amazonas. Essas madeireiras geravam apenas $7 \%$ dos empregos e produziam somente $5 \%$ da madeira processada (em geral de baixa qualidade) do Estado. (IMAZON, 2015).

No caso específico do Estado do Pará, as espécies madeireiras mais exploradas são ipê 
(Tabebuia sp.), cedro (Cedrela odorata), freijó (Cordia sp.), maçaranduba (Manilkara sp.), angelim pedra (Hymenolobium sp.), angelim vermelho (Dinizia excelsa), jatobá (Hymenaea sp.), louro (Nectandra sp.), muiracatiara (Astronium sp.), tauari (Couratari sp.), faveira (Pterodon sp.), cumaru (Dipteryx sp.), piquiá (Caryocar sp.), tatajuba (Bagassa guianensis), e marupá (Simaruba amara).

$\mathrm{Na}$ zona estuarina do Estado, onde predominam as florestas de várzea, as espécies mais exploradas são andiroba (Carapa guianensis), anani (Symphonia globulifera), jacareúba (Calophyllum brasiliense), macacaúba (Platymiscium sp.), pau-mulato (Calycophyllum spruceanum), pracuúba (Mora sp.) e virola (Virola surinamensis).

Para a indústria de laminados e compensados, as principais espécies utilizadas são a amescla (Trattinickia sp.), Currupixá (Micropholis melinoniana), copaíba (Copaifera sp.), faveira (Pterodon sp.), paricá ou pinho cuiabano (Schizolobium amazonicum), etc. (IMAZON, 2015).

A transformação de plantações em florestas não é um simples jogo de palavras, mas trata-se de uma mudança conceitual muito significativa, e que incorpora as questões ambiental e social como partes integrantes do processo. Essa perspectiva multidimensional e multiescalar de manejo incorpora as complexidades e as incertezas inerentes aos ecossistemas naturais, consistindo numa abordagem sistêmica da cadeia produtiva da madeira. Assim, a análise da cadeia produtiva da madeira sob o novo prisma de um novo ambiente de negócios, estabelece que é de extrema importância possuir atuação técnica e cientificamente visando ampliação da capacidade de oferta, minimização de impactos ambientais e inserção de preceitos sociais na estratégia de produção. 


\section{Metodologia}

O Pará é o Estado brasileira com o segundo maior território uma área de 1247954,666 $\mathrm{km}^{2}$, e o maior exportador de madeira em toras, o maior PIB da região norte do Brasil, e tem as maiores empresas exploradoras de madeira nativa do Barsil. (CNI, 2017).

Tabela 1. Divisão macro geopolítica do Estado do Pará.

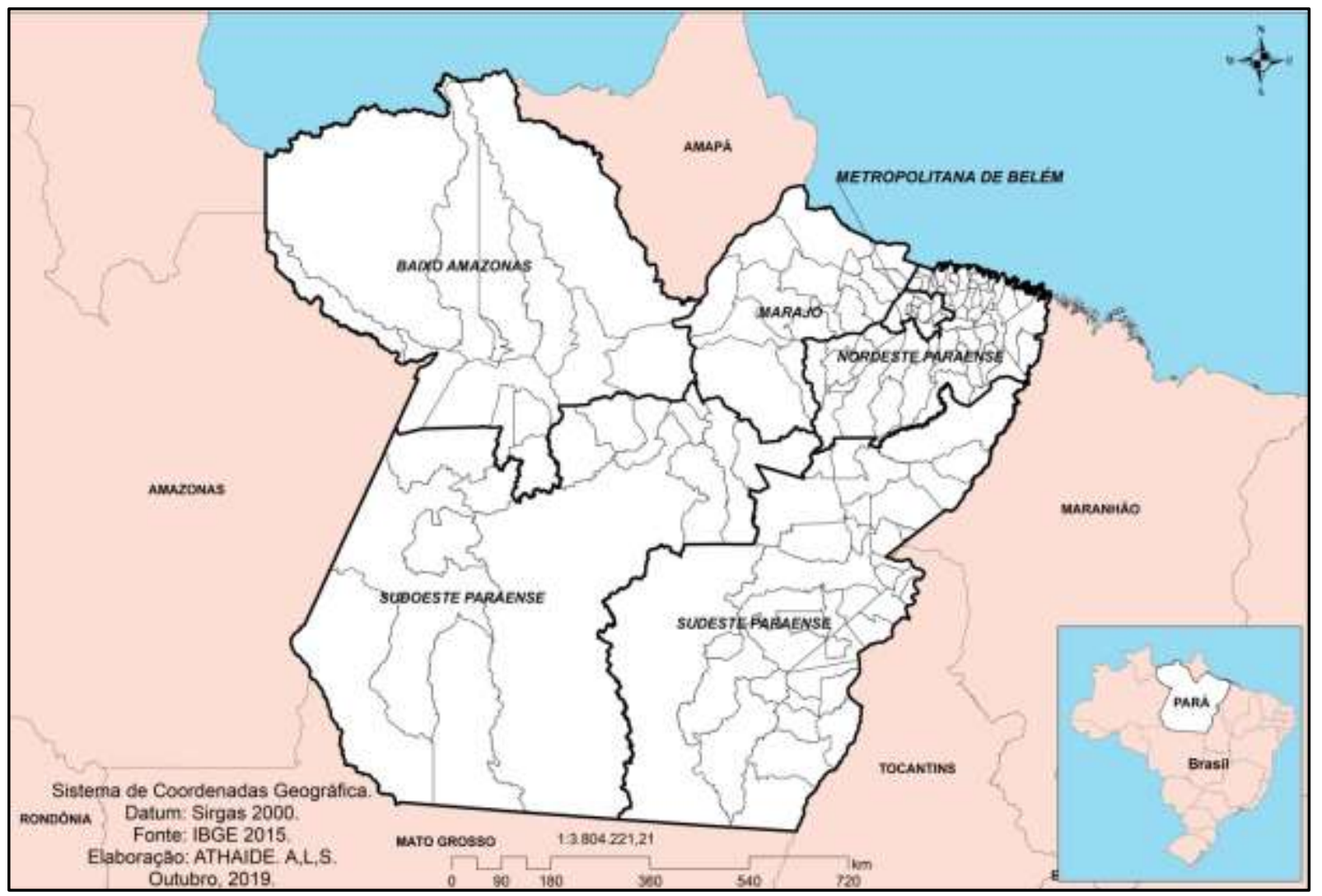

Fonte: Própria (2019)

Os dados foram coletados na plataforma on-line do Ministério da Indústria, Comércio Exterior e Serviços (MDIC), disponibilizados no Sistema do MDIC de Estatística do Comercio Exterior (Comex Stat), que são extraídas do SISCOMEX e baseados na declaração de exportadores e importadores (BRASIL, 2019), referentes ao Estado do Pará no período de 2000 a 2015. Para melhor visualização dos dados, os mesmos foram classificados em quatro categorias sendo: madeira compensada, madeira serrada, madeira bruta (Coníferas) e movelaria. Além de bibliografia que trata sobre o assunto em bases online de pesquisa.

\section{Variáveis utilizadas}

As variáveis utilizadas foram: Quantidade de madeira exportada em quilograma líquido (Kg), Valor FOB (US\$) da quantidade exportada. Para melhor apresentação dos dados 
foi feita a transformação de quilograma (Kg) para tonelada ( $\mathrm{T}$ ) e posteriormente foi determinado o valor monetário da madeira por tonelada através da equação:

$$
\mathbf{P}=\mathrm{V} / \mathbf{Q}
$$

Onde:

$\mathrm{P}=$ Preço em US\$/Tonelada; V= Valor anual da produção;

$\mathrm{Q}=$ Quantidade anual exportada em toneladas;

\section{Cálculo das Taxas Geométricas de Crescimento (TGC\%)}

As taxas geométricas de crescimento (TGC) foram calculadas através da formula:

$$
\text { TGC= PROJ.LOG }(x 1 ; X n)-1.100
$$

Onde:

TGC = Taxa geométrica do Crescimento (TGC);

Proj.Log= Projeção Logarítmica do período;

\section{Cálculos da Taxa de Variação (TV\%)}

A taxa de variação (TV\%) foi calculada através da formula:

$$
T V=(X n-X 1) / X 1.100
$$

Onde:

$\mathrm{TV}=$ Taxa de variação;

$\mathrm{X} 1=$ Período inicial;

$\mathrm{Xn}=$ Período Final;

\section{Resultados e Discussão}

Os dados obtidos no período de 2000 a 2015 pela base de dados ComexStat, obtiveram os seguintes resultados para madeira compensada, a média foi de aproximadamente de 72.415 Toneladas $( \pm 269,1)$, com máxima de 196.490 Toneladas em 2004 e mínima de 1518 Toneladas em 2014 (FIGURA 2a.), para os valores em Free On Board (FOB) a média obtida em dólares (US\$) foram de aproximadamente 40.541.683 milhões de dólares, com máxima de 103.581.723 milhões de dólares em 2004 e mínima de 1.727.738 milhões de dólares em 2014 (FIGURA 2a.); para madeira serrada o valor obtido médio foi de aproximadamente de 357.818 Toneladas $( \pm 598)$, com máxima de 692.217 Toneladas no ano de 2004 e mínima 80.784 Toneladas em 2013 (FIGURA 2b.), os valores em FOB (US\$) a média obtida foram de 162.355.318 milhões de dólares, com valor máximo de 337.534.280 milhões de dólares no ano de 2007 e mínimo de 58.619 .741 milhões 
de dólares em 2015 (FIGURA 2b.).

Os resultados para madeira bruta (conífera) a média de peso exportada obtida foi de 742 Toneladas $( \pm 27,24)$, com máxima de 3045 Toneladas no ano de 2002 e mínima de 9,8 Toneladas em 2013 (FIGURA 2c.), o valor médio obtido de 373.214 mil dólares, sendo seu máximo de 1.094.154 milhões de dólares no ano de 2002 e mínima de 20.733 mil dólares (FIGURA 2c.); e para movelaria a média obtida de aproximadamente 4350 Toneladas ( $\pm 65,95)$, com máxima de 10775 Toneladas no ano de 2003 e mínima de 64 toneladas em 2015 (FIGURA 2d.), o valor médio FOB obtido de 4.983 .568 milhões de dólares, com valor máximo de 10.718 .889 milhões de dólares no ano de 2003 e mínimo de 323.981 mil dólares em 2015 (FIGURA 2d.). 
Figura 2. Interação entre Toneladas (T) e Valor FOB US\$ (milhões). A) Para madeira compensada. B) Para madeira serrada. C) Para madeira bruta (coníferas) e D) Para Móveis no desempenho das exportações no Estado do Pará, no período de 2000-2015.
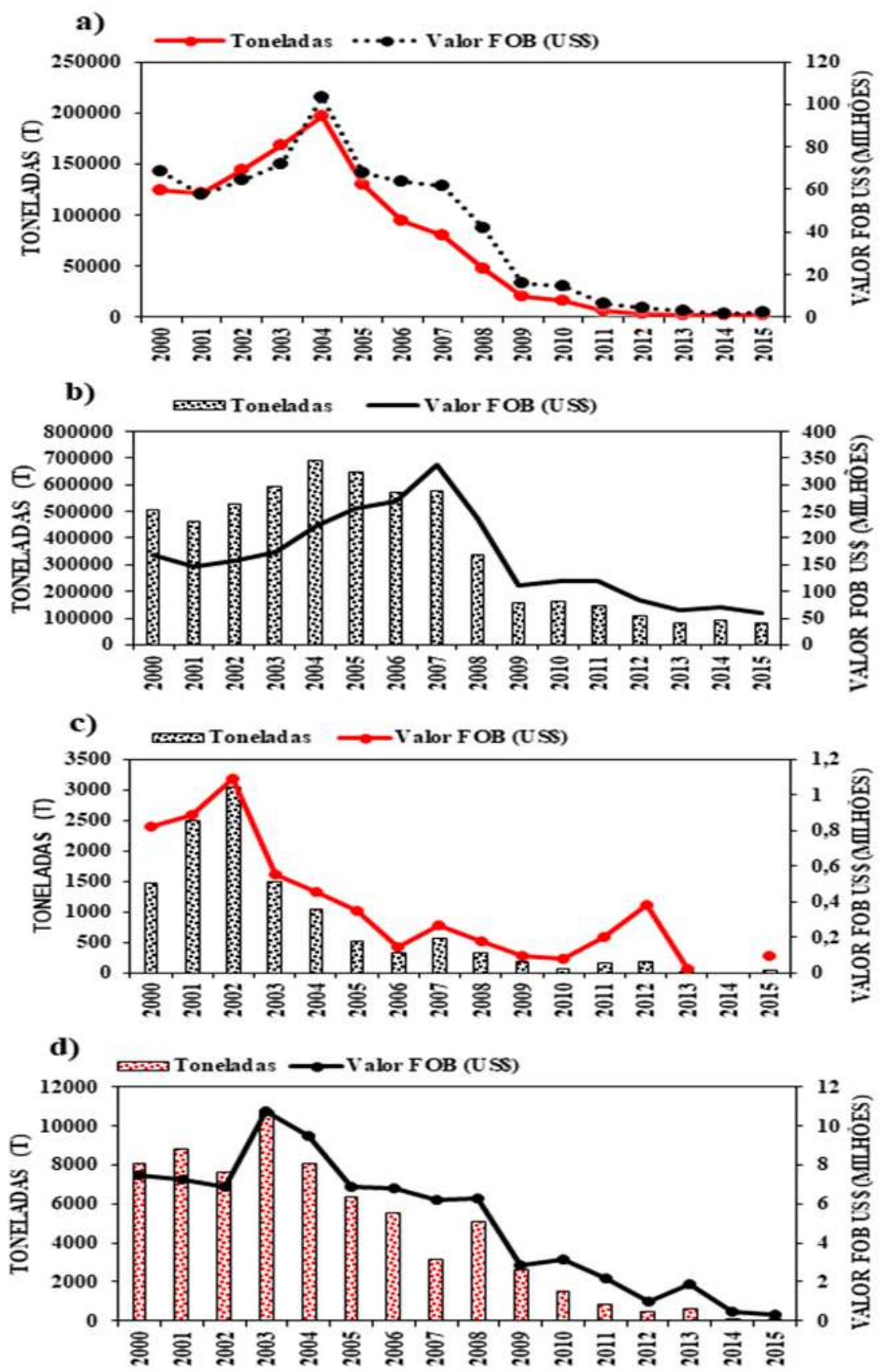

Fonte: Própria (2019)

A partir dos dados processados houve o cálculo de Taxa de Variação (TV\%) e Taxa Geométrica de Crescimento (TGC\%) no período de 2000 a 2015 (Tabela 1), referentes a Toneladas por ano. 
Tabela 2. Taxa de variação e taxa geométrica do crescimento referente a variável (T/Ano).

\begin{tabular}{ccccc}
\hline & Compensada & Serrada & Coníferas & Móveis \\
\hline TV (\%) & $-98 \%$ & $-84 \%$ & $-97 \%$ & $-99 \%$ \\
TGC (\%) & $-29 \%$ & $-15 \%$ & - & $-27 \%$ \\
\hline Fonte: Própria (2019) & & &
\end{tabular}

Nota-se a diminuição da oferta de madeira para exportação nas quatro categorias analisadas (FIGURA 2). De acordo com Simões, Silva e Silva E Silva (2015), essa retração na exportação da indústria madeireira ocorreu, devido ao cerco que o Governo Federal impôs ao setor pelo combate a exploração ilegal de madeira e ao fortalecimento da gestão em florestas públicas pela implantação da Lei $\mathrm{n}^{\circ} 11.284 / 06$, fazendo com que no período de 2005 a 2012, houvesse uma intensa crise que levaram há uma redução de $72 \%$ na exportação de produtos de origem madeireira.

Na FIGURA 3 é possível observar a variável preço com relação a quantidade exportada (US\$/T), onde verifica-se que o preço aumenta conforme a quantidade exportada diminui, para esta variável foram calculadas Taxa de variação (TV\%) e Taxa Geométrica do crescimento (TGC\%) (Tabela 2), onde para madeira compensada se tem uma taxa de variação positiva de $67 \%$ para o período e taxa geométrica de crescimento de $7 \%$ ao ano (FIGURA 3a). Para madeira serrada tem-se uma taxa de variação positiva de $122 \%$ para o período e uma taxa geométrica do crescimento de $8 \%$ ao ano (FIGURA 3b). Com relação a madeira bruta provenientes de coníferas observa-se uma taxa de variação de $288 \%$ para o período (FIGURA 3c). Com relação a movelaria apresentou uma taxa de variação positiva de $422 \%$ e uma taxa geométrica de crescimento de $12 \%$ ao ano (FIGURA $3 \mathrm{~d}$ ).

Tabela 3. Taxa de variação e taxa geométrica do crescimento referente a variável (US\$/T).

\begin{tabular}{ccccc}
\hline & Compensada & Serrada & Coníferas & Móveis \\
\hline TV (\%) & $67 \%$ & $122 \%$ & $288 \%$ & $442 \%$ \\
TGC (\%) & $7 \%$ & $8 \%$ & - & $12 \%$ \\
\hline
\end{tabular}

Fonte: Própria (2019)

Segundo VALVERDE et al. (2006) o efeito do crescimento do comercio mundial e a composição da pauta refletem a influência de fatores externos no desempenho das exportações. Já o efeito do destino das exportações e a competitividade estão relacionados com fatores internos. Segundo (Barreto et al., 2002) a falta de profissionais treinados e a não utilização de equipamentos adequados resultam em danos excessivos a floresta. 
Figura 3. Interação entre madeira compensada (T) e Preço (US\$/T). B. Para madeira serrada (T) e Preço (US\$/T). C. Para madeira bruta (Conífera) (T) e Preço (US\$/T) e D. Para movelaria exportada e Preço (US\$/T), no período de 2000 a 2015, no Estado do Pará.
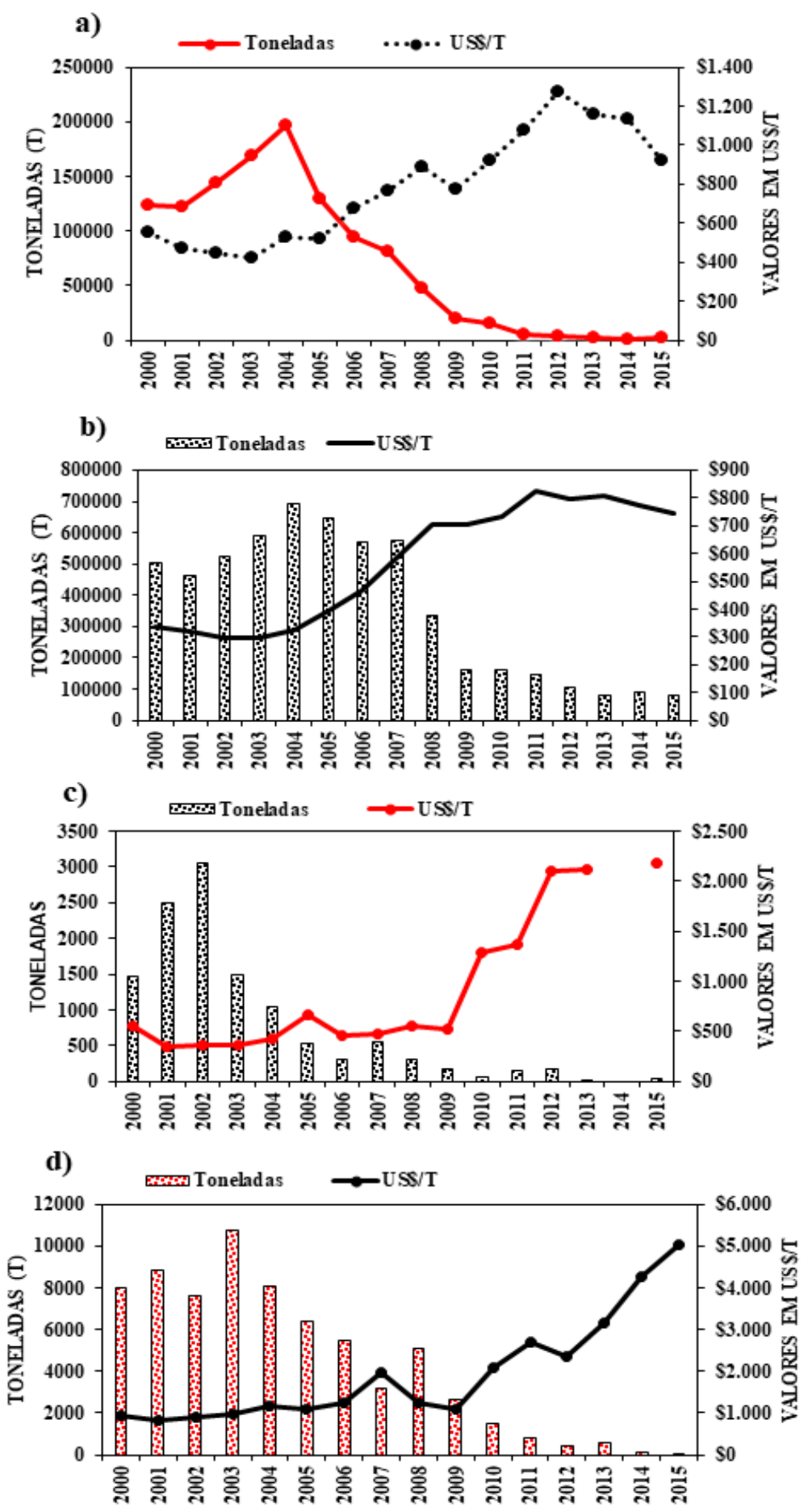

Fonte: Própria (2019)

A maioria da produção madeireira da região amazônica pode ser considerada predatória ou proveniente de desmatamento, e que as produções sustentáveis em sua maioria são oriundas de planos de manejo deficientes (ALMEIDA, et al., 2010).

No estado do Pará no período de 2000 a 2005 em sua balança comercial de exportação notou- 
se que $8,8 \%$ dos produtos exportados do estado eram provenientes da indústria madeireira, este período pode ser considerado como o ápice da exportação de madeira no estado. Pois posterior a este período observa-se um grande declínio nas exportações de madeira, sendo no período de 2006 a 2010 os índices caíram para 2,8\% e no período de 2011 a 2015 esta taxa despenca para $0,6 \%$ podendo ser observando na Tabela 3 .

Tabela 4. Balança comercial de exportação do estado do Pará com relação a exportação de madeira no período de 2000 a 2015.

\begin{tabular}{cccccccc}
\hline & $\mathbf{2 0 0 0 - 2 0 0 5}$ & \multicolumn{2}{c}{$\mathbf{2 0 0 6 - 2 0 1 0}$} & \multicolumn{2}{c}{$\mathbf{2 0 1 1 - 2 0 1 5}$} \\
Classificação & Preço & $\%$ & Preço & $\%$ & Preço & $\%$ \\
\hline Compensado & $\$ 433.524 .745,00$ & 2,4 & $\$ 197.704 .015,00$ & 0,4 & $\$ 17.438 .167,00$ & 0,02 \\
\hline Serrada & $\$ 1.125 .636 .494,00$ & 6,2 & $\$ 1.075 .041 .236,00$ & 2,3 & $\$ 397.007 .366,00$ & 0,5 \\
\hline Folhosa & - & 0 & $\$ 67.051,00$ & 0,0001 & $\$ 1.953 .167,00$ & 0,003 \\
Conífera & $\$ 4.146 .662,00$ & 0,02 & $\$ 758.943,00$ & 0,002 & $\$ 692.608,00$ & 0,0009 \\
Móveis & $\$ 48.640 .484,00$ & 0,3 & $\$ 25.239 .533,00$ & 0,1 & $\$ 5.857 .066,00$ & 0,01 \\
Total & $\$ 1.611 .948 .385,00$ & 8,8 & $\$ 1.298 .810 .778,00$ & 2,8 & $\$ 422.948 .374,00$ & 0,6 \\
\hline $\begin{array}{c}\text { Total } \\
\text { balança }\end{array}$ & $\$ 18.224 .582 .797,00$ & $\$ 46.459 .756 .460,00$ & & & \\
comercial & & & & & & & \\
\hline
\end{tabular}

Fonte: Própria (2019)

Segundo Noce, et al. (2003) a partir do momento que um país exporta produto primário há perca de espaço no mercado internacional, pois a diferença entre o valor da matéria prima e o produto beneficiado que pode ser comercializado com maior valor no mercado internacional, a venda de produtos beneficiados auxilia nos ganhos sociais de recursos que facilita também a movimentação da cadeia produtiva que atrai demanda para novos setores de fabricação.

Para Franck et al. (2018), apesar de os produtos madeireiros perderem espaço na balança comercial do Estado do Pará, a atividade madeireira desponta para um futuro promissor, devido a reorganização do setor que está sendo implantada pelo poder público e aos vários segmentos do mercado que ainda utilizam a madeira como matéria-prima. E a partir dos dados obtidos por Simões, Silva e Silva e Silva (2015), as exportações de produtos madeireiros no estado que no ano de 2003 representavam 14\% da balança comercial, em 2011 diminuiu para apenas $2 \%$, porem a tendência é de estabilidade do mercado e um progressivo aumento das exportações para os próximos anos. Como observou-se em dados recentes do Ministério da Indústria, Comércio Exterior e Serviços (BRASIL, 2019), em que nos anos de 2017 e 2018 as taxas de exportação estabilizaram-se em 0,8\% da balança comercial do Estado do Pará. 


\section{Conclusões}

Portanto a conclusão obtida, através das análises dos dados pela variável madeira exportada (T) e o Preço FOB nota-se um declínio no período de 2000 a 2015, devido às políticas públicas implantadas na década passada de combate ao desmatamento ilegal na região amazônica fez com que os índices de exportação de produtos de origem florestal perdessem espaço na balança comercial de exportação do Estado do Pará.

\section{Referências}

ALMEIDA, A.N.; ANGELO, H.; SILVA, J.C.G.L.; HOEFLICH, V.A. Mercado de madeiras tropicais: substituição na demanda de exportação. Acta Amazonica, Manaus, v.40,n.1,p.119-126.2010. Disponível em: 〈http://www.scielo.br/pdf/aa/v40n1/v40n1a15.pdf〉. Acesso em: 20 jan 2019.

ARAÚJO, C. T. D. Mudanças na paisagem da região de Tailândia, estado do Pará, entre os anos de 1985 a 2015. 2017. Dissertação (Mestrado em Ciências Florestais) Departamento de Engenharia Florestal - UnB, Brasília.

BARRETO, P.; SOUZA JR., C.; GALVÃO, C.; ALBUQUERQUE, K.; GISELlE, A.; MACEDO, M.; FIRESTONE, L. 2002. Controle do desmatamento da exploração de madeira na Amazônia: diagnóstico e sugestões. Relatório Técnico do IMAZON - Versão preliminar para discussão. MMA/PPG7/ProManejo. Belém. 36 pp.

BUAINAIN, A. M; BATALHA, M. O: Série agronegócios. Cadeia produtiva da madeira, vo.6, p.13, 2007. Disponível em: < https://books.google.com.br/books?hl=pt$\mathrm{BR} \& \mathrm{lr}=\& \mathrm{id}=\mathrm{q} 9 \mathrm{wOAQAAIAAJ} \& \mathrm{oi}=\mathrm{fnd} \& \mathrm{pg}=\mathrm{PT} 14 \& \mathrm{dq}=$ cadeia + produtiva + da + madeira + no + Par\%C3\%A1\&ots=cKytHDYTys\&sig=DivF2yd5GwupaZY_QEPWIr_uTiw\#v=onepage\&q= cadeia $\% 20$ produtiva $\% 20 \mathrm{da} \% 20$ madeira $\% 20$ no $\% 20 \mathrm{Par} \% \mathrm{C} 3 \% \mathrm{~A} 1 \& \mathrm{f}=$ false $>$. Acesso em: 11 de janeiro de 2019.

BRASIL, Ministério da Industria, Comércio Exterior e Serviços. Sistema para consultas e extração de dados do comércio exterior brasileiro (Comex Stat). 2019. Disponível em: < http://comexstat.mdic.gov.br/pt/home>. Acesso em: 15 de Janeiro de 2019. 
DA SILVA MAZZOCHIN, M. Dinâmica e espacialização das exportações de madeira do Brasil. FURG, Cadernos. v. 6, n. 1, 2013.

FRANCK, A. G. S., et al. ANÁLISE EMPÍRICA DO PADRÃO DE ESPECIALIZAÇÃo DO COMÉRCIO INTERNACIONAL DO ESTADO DO PARÁ (1999-2016). Revista da Universidade Vale do Rio Verde, Santa Maria, v. 16, n. 1, p.1-21, jul. 2018. Disponível em: <http://periodicos.unincor.br/index.php/revistaunincor/article/view/4403>. Acesso em: 10 jan. 2019.

HOMMA, A. K. O. Extrativismo vegetal na Amazônia: história, ecologia, economia e domesticação. Embrapa Amazônia Oriental-Livro científico (ALICE), 2014.

IBAMA. Operação Arco de Fogo fecha madeireiras e carvoarias em Tailândia, Pará. Disponível em:<http://ibama.gob.br/notícias-2008/operacaoarcodefogofechamadereirasecarvoarias-em-tailandia-para>. Acesso em: 24 jan. 2019.

IMAZON. Polos Madeireiros do Estado do Pará, Disponível em: <https: //imazon.org.br/polos-madeireiros-do-estado-do-para/>. Acesso em: 08 fevereiro 2019.

OLIVEIRA, R. S.; ANDRADE, F. W. C. COMÉRCIO DE MADEIRAS DE FLORESTAS NATIVAS NA MESORREGIÃO DO SUDESTE PARAENSE. II Congresso Brasileiro de Ciência e Tecnologia da Madeira. Sociedade Brasileira de Ciência e Tecnologia da Madeira. Anais. Belo Horizonte-MG. 2015.

NOCE, R. et al. Desempenho do Brasil nas exportações de madeira serrada. Revista Árvore, v. 27, n. 5, 2003.

SFB. Serviço Florestal Brasileiro. Manejo Florestal. Brasília, 2015. Disponível em: <http://www.florestal.gov.br/pngf/manejo-florestal/apresentacao>. Acesso em: 08 fevereiro 2019.

SANTANA, A. C.; SANTOS, M. A. S.; SANTANA, A. L; YARED, J. A. G: O valor econômico da extração manejada de madeira no baixo amazonas, estado do Pará. Revista Árvore, Viçosa-MG, v.36, n.3, p.527-536, 2012.

SIMÕES, J. E. M.; SILVA e SILVA, E. da; SILVA, D. C. C. CADERNOS CEPEC. Análise da Exportação de Madeira do Pará em período recente, v. 4, n. 2, 2015. 
VALVERDE, S. R.; SOARES, N. S.; SILVA, M. L. Desempenho das exportações brasileiras de celulose. Revista Árvore, v. 30, n. 6, p. 1017-1023, 2006. 